\title{
Üst ve Alt Gastrointestinal Sistem Endoskopisi Yapılan Çocuklarda Gastrointestinal Kanamalarının Retrospektif Değerlendirilmesi
}

\author{
Retrospective Evaluation of Gastrointestinal Bleeding in Children with Upper and \\ Lower Gastrointestinal System Endoscopy
}

\author{
Engin Gerçeker ${ }^{1}$, Erhun Kasırga ${ }^{2}$, Güzide Doğan ${ }^{3}$, Buse Soysal $^{1}$ \\ ${ }^{1}$ S.B.Ü. Dr. Behçet Uz Çocuk Hastalıkları ve Cerrahisi Eğitim ve Araştırma Hastanesi, İzmir Türkiye \\ ${ }^{2}$ Maltepe Üniversitesi Tip Fakültesi Çocuk Sağlı̆̆ı ve Hastalıkları AnabilimDalı, İstanbul \\ ${ }^{3}$ Bezm-i Alem Vakı Üniversitesi Tip Fakültesi Hastanesi, İstanbul \\ Yazışma Adresi / Correspondence: \\ Engin Gerçeker \\ S.B.Ü. Dr. Behçet Uz Çocuk Hastalıkları ve Cerrahisi Eğitim ve Araştırma Hastanesi, İzmir Türkiye \\ T: +90530641 $1369 \quad$ E-mail : engingerceker83@gmail.com \\ Geliș Tarihi / Received : 22.08.2020 Kabul Tarihi / Accepted : 04.12.2020 \\ Orcid : \\ Engin Gerçeker https://orcid.org/0000-0002-8136-2980 \\ Erhun Kasırga https://orcid.org/0000-0002-8113-286X \\ Güzide Doğan https://orcid.org/0000-0003-4291-7282 \\ Buse Soysal https://orcid.org/0000-0002-0191-5283 \\ ( Sakarya Tip Dergisi / Sakarya Med J 2021, 11(1):53-60 ) DOI: 10.31832/ smj.784167
}

\footnotetext{
Öz

Amaç Bu çalıșma, çocuklarda gastrointestinal sistem (GíS) kanama sıklığını, kanamanın etiyolojik nedenlerini ve sosyodemografik değișkenlere göre dağılımını ortaya koymak amacıyla yürütülmüștür.

Gereç ve Aralık 2013-Kasım 2015 tarihleri arasında Celal Bayar Üniversitesi Tip Fakültesi Çocuk Gastroenteroloji Bölümüne GİS kanaması nedeni ile başvuran ve endoskopik Yöntem inceleme (özefagogastroduodenoskopi ve kolonoskopi) yapılan 70 çocuk hastanın verileri retrospektif olarak değerlendirilmiștir.

Bulgular Hastaların (35 kız, 35 erkek) ortalama yașları 11 \pm 4.8 yıl (2-17 yll) idi, 43 hastada (\%61.4) üst GİS kanaması, 27 hastada (\%38.6) alt GİS kanaması bulundu. Üst GİS kanaması olan hastaların 16'sının (\% 37.3) nonsteroidantiinflamatuar ilaç (NSAIİ) veya aspirin kullandığı ve bu hastaların 8'inin 2-5 yas arasında olduğu saptandı. Hastaların ortalama hemoglobin değeri 11.4 \pm 2.3 (4.8-16.9) g/dL, ortalama hematokrit değeri 34.6 \pm 7.0 (15-52) idi. Üst Gís kanamalı 16 hastada (\% 37.2) histopatolojik inceleme sonucunda H. pylori pozitifliği saptand. Alt GİS kanamalı 7 hasta (\% 25.9) inflamatuar bağırsak hastalığı tanısı aldı. Karaciğer sirozu olan 1 hasta özefagus varis kanaması nedeniyle kaybedildi.

Sonuç Cocukluk çağında sık kullanılan NSAIII’ler tedavi dozlarında bile üst GİS kanamalarına neden olabilir. Gereksiz NSAIİ kullanımından kaçınılmalıdır. Adölesan dönemdeki alt GİS kanamalarını önemli nedenlerinden birisinin inflamatuar bağırsak hastalıkları olduğu unutulmamalıdır.

Anahtar Endoskopi; çocuk; gastrointestinal kanama

Kelimele

Abstract

Objective This study was conducted to reveal the frequency of gastrointestinal system (GI) bleeding, etiological causes of bleeding, and its distribution according to sociodemographic variables in children.

Seventy pediatric patients' data who applied to Celal Bayar University Faculty of Medicine, Department of Pediatric Gastroenterology due to GIS bleeding between December 2013 and November 2015 and underwent endoscopic examination (esophagogastroduodenoscopy and colonoscopy) were evaluated retrospectively.

Results The patients' (35 female, 35 male) mean age was $11 \pm 4.8$ years (2-17 years), 43 patients (61.4\%) had upper GI bleeding, and 27 patients (38.6\%) had lower GI bleeding. It was found that 16 (37.3\%) of the patients with upper GI bleeding were using nonsteroidal anti-inflammatory drugs (NSAIDs) or aspirin, and 8 of these patients were between 2-5 years. The mean hemoglobin level of patients was $11.4 \pm 2.3(4.8-16.9) \mathrm{g} / \mathrm{dL}$, and the hematocrit level was $34.6 \pm 7.0$ (15-52). Sixteen patients (37.2\%) with upper GI bleeding were positive for H. pylori at histopathological examination. Seven patients (25.9\%) with lower GI bleeding were diagnosed with inflammatory bowel disease. One patient with liver cirrhosis died due to esophageal variceal bleeding.

Conclusion The NSAIDs are commonly used in childhood can lead to upper GI bleeding, even in therapeutic doses. Unnecessary NSAIDs use should be avoided. One of the important causes of lower GI bleeding in adolescents should be noted that inflammatory bowel disease.
} 


\section{GIIRIŞ}

Gastrointestinal sistem (GİS) kanamaları hekimler açısından önemli pediatrik acil durumlardan biridir. Çocuklarda gastrointestinal kanama, anal fissür veya inek sütü proteini alerjisi ile ilişkili dışkıdaki az miktardaki kanamadan, portal hipertansiyon veya peptik ülser hastalığına bağlı yaşamı tehdit edici kanamalara kadar geniş bir spektrumu içermektedir. Ciddi kanama, hayatı tehdit eden acil klinik tabloya yol açabileceğinden hızlı tanı konulup uygun tedavi başlanılmalıdır. ${ }^{1}$

Gastrointestinal sistem kanamaları, üst ve alt olarak iki gruba ayrılmaktadır. Üst GİS kanamalar, özefagusun üst kısmı ile Treitz ligamenti arası herhangi bir yerde lümen içine kanamalardır. Treitz ligamentinin distalinden olan kanamalar ise alt GIS kanaması olarak tanımlanmaktadır. ${ }^{1}$ GİS kanamaların çoğu üst GİS kaynaklıdır. Üst GİS kanama nedenleri yaşa, coğrafi bölgeye göre değişebilmektedir. Doğu ülkelerinde en sık neden portal hipertansiyona (PHT) bağlı iken, batı toplumlarında gastrik ve duodenal ülser gibi varis dışı nedenlere bağlı gelişebilmektedir. Çocukluk çağında sık olarak kullanılan aspirin, ibuprofen gibi non-steroid anti-inflamatuvar ilaç (NSAİi) kullanımına bağlı kanamalar görülmektedir. ${ }^{2}$

Alt GİS kanamalar ise, yenidoğan döneminde anal fissür, nekrotizan enterokolit (NEK), allerjik kolit; süt çocukluğu döneminde anal fissür, invajinasyon, okul öncesi ve okul çağı döneminde juvenil polip, inflamatuar bağırsak hastalığı (İBH), Meckel divertikülü, bakteriyel enterit gibi nedenlere bağlı olabilir. ${ }^{3}$ Pediatrik populasyonda GİS kanamalarında tanı-tedavide endoskopik ve radyolojik yöntemler gelişmişse de, GİS kanamaların etyolojisine ilişskin bilgiler yetersizdir. GİS kanaması olan çocuğunun durumu stabilleştikten sonra, kanamanın yeri, kanamaya neden olabilecek patolojilerin araştırılması oldukça önemlidir.

$\mathrm{Bu}$ bilgiler doğrultusunda bizim çalışmamızdaki amacımız üst ve alt GİS endoskopisi yapılan çocuklarda GİS kanama sıklığını, kanamanın etiyolojik nedenlerini ve sosyodemografik değişkenlere göre dağılımını retrospektif olarak incelemektir.

\section{GEREÇ ve YÖNTEMLER}

Bu tanımlayıcı araştırmanın örneklemini, Aralık 2013-Kasım 2015 tarihleri arasında bir üniversite hastanesinin Pediatrik Gastroenteroloji Bilim Dalında üst ve alt GİS endoskopisi yapılan 70 hasta oluşturmuştur. Yenidoğan döneminde olan, kanama diyatezi olan, sepsis öyküsü olan ve Munchausen by Proxy sendromu tanisı alan hastalar araştırmadan dışlanmıştır.

Araştırma verileri toplanmadan önce, Celal Bayar Üniversitesi Hafsa Sultan Hastanesi Yerel Etik Kurulundan onay alınmıştır (03/08/2016 20.478.486-282). Literatür doğrultusunda geliştirilen anket formu aracıllğıyla, alt ve/veya üst GİS kanama teşhisiyle Pediatrik Gastroenteroloji Bilim Dalında alt veya üst GISS endoskopisi yapılan 70 hasta retrospektif olarak tanımlanmıştır. Çalışma Helsinki Deklarasyonu Prensipleri’ne uygun olarak yürütülmüştür.

Aralık 2013-Kasım 2015 tarihleri arasında endoskopi yapılan 70 hastanın dosyaları incelenerek, hastaların yaş, cinsiyet, GİS kanaması tipi, geçirilmiş GİS kanaması öyküsü, ailede GİS kanaması öyküsü, ailede ülser öyküsü, ailede geçirilmiş GİS operasyonu öyküsü, üst ve alt GİS kanama etyolojileri, üst ve alt GİS kanaması olan hastaların başvuru yakınmaları, ilaç kullanım öyküsü, fizik muayenede saptanan bulgular, hemoglobin ( $\mathrm{Hb})$, hematokrit (Htc), ortalama eritrosit hacmi $(\mathrm{OEH})$, karaciğer ve böbrek fonksiyon testleri, koagulasyon parametreleri, histopatolojik inceleme sonuçları, $H$. pylori öyküsüne ilişkin bilgiler elde edilmiştir. Hastalara endoskopi işlemi Olympus Exera II CV180 Pediatrik Video Endoskop ve Kolonoskop ile yapılmıştır. Hastaların yaşları 2-17 arasında değişmektedir. Hastalar 2-5 yıl, 6-11 yıl ve 12-17 yıl olarak gruplandırılarak, yaş gruplarına göre alt ve üst GİS kanama etiyolojileri değerlendirilmiştir. Kanama tipine göre (alt ve üst GİS kanama) hastaların başvuru yakınmaları, ilaç kullanımı öyküsü, hastalarda görülen semptomlar, fizik muayene 
bulguları değerlendirilmiştir. Hastaların $\mathrm{Hb}$, Htc ve $\mathrm{OEH}$ değerlerine ilişkin ortalamalar hesaplanmıştır. Kanama tipi ve histopatoloji sonuçları değerlendirilmiştir. SPSS 23.0 for Windows istatistik programı kullanarak, hastaların tanıtıcı özellikleri sayı ve yüzdelik bulgular olarak değerlendirilmiştir.

\section{BULGULAR}

Hastaların yaş ortalaması $11 \pm 4.8$ yll (2-17 yll) olup, \% 55.8'i 12-17 yaş grubunda, \% 50.0’si erkektir. Hastaların \% 61.4'üüst GIS kanamasıdır ve \% 34.3'ünde geçirilmiş GİS kanaması öyküsü vardır. Ailelerinin \% 81.1'inde GİS kanaması ya da ülser öyküsü mevcuttur (Tablo 1).

\begin{tabular}{|c|c|c|}
\hline Değișkenler & Sayı & $\%$ \\
\hline \multicolumn{3}{|l|}{ Yaş Grubu } \\
\hline $2-5$ yaş & 14 & 20.0 \\
\hline 6-11 yaş & 17 & 24.2 \\
\hline 12-17 yaş & 39 & 55.8 \\
\hline \multirow{2}{*}{ Yaş ortalaması } & $\mathrm{M} \pm \mathrm{SS}$ & Min.-Max. \\
\hline & $11 \pm 4.8 \mathrm{yll}$ & $2-17$ \\
\hline Cinsiyet & Sayı & $\%$ \\
\hline $\mathrm{K} 1 \mathrm{z}$ & 35 & 50.0 \\
\hline Erkek & 35 & 50.0 \\
\hline \multicolumn{3}{|l|}{ Kanamanın tipi } \\
\hline Alt Gİs & 27 & 38.6 \\
\hline Üst GİS & 43 & 61.4 \\
\hline \multicolumn{3}{|c|}{ Geçirilmiş GİS kanaması } \\
\hline Evet & 24 & 34.3 \\
\hline Hayır & 46 & 65.7 \\
\hline \multicolumn{3}{|c|}{ Ailede GİS kanaması öyküsü } \\
\hline Evet & 9 & 12.9 \\
\hline Hayır & 61 & 81.1 \\
\hline \multicolumn{3}{|c|}{ Ailede ülser öyküsü } \\
\hline Evet & 9 & 12.9 \\
\hline Hayır & 61 & 81.1 \\
\hline \multicolumn{3}{|c|}{ Ailede geçirilmiş GİS operasyonu öyküsü } \\
\hline Evet & 5 & 7.1 \\
\hline Hayır & 65 & 92.9 \\
\hline Toplam & 70 & 100.0 \\
\hline \multicolumn{3}{|c|}{ M: Ortalama, SS:Standart sapma, GİS:Gastrointestinal } \\
\hline
\end{tabular}

Üst GİS kanamalı hastaların etyolojisi incelendiğinde; \% 69.8 'inde eroziv gastrit/bulbit, \% 16.2'sinde gastrik-duodenal ülser, \% 7'sinde özefageal varis, \% 4.7'sinde özefajit ve $\% 2.3$ 'ünde vasküler malformasyon saptanmıştır. Yaş gruplarına göre etyoloji incelendiğinde ise, 2-5 yaş grubunda (\% 55.6), 6-11 yaş grubunda (\% 81.9), 12-17 yaş grubunda (\% 69.6) en sık eroziv gastrit, bulbit saptanmıştır.

Alt GİS kanamalı hastaların etyolojisi incelendiğinde; \% 29.6'sinda İBH, \% 14.8'sinde hemoroid, \% 14.8'sinde anal fissür, \% 14.8'sinde rektal polip, \% 11.1'inde soliter rektal ülser, \% 7.4'ünde normal kolonoskopik inceleme (Meckel divertikülü), \% 3.7'sinde familyal polipozis koli ve \% 3.7'sinde arteriovenöz malformasyon saptanmıştır. Yaş gruplarına göre etyoloji incelendiğinde ise, 2-5 yaş grubunda en sik anal fissür (\% 40.0) ve rektal polip (\% 40.0), 6-11 yaş grubunda en sık İBH (\% 33.3) ve anal fissür (\% 33.3), 12-17 yaş grubunda en sık İBH (\% 31.3) ve hemoroid (\% 25.0) saptanmıştır.

Alt GİS kanamalı hastaların \% 92.6'sında rektal kanama, \% 70.4'ünde kabızlık, üst GİS kanamalı hastaların ise \% 83.7'sinde ağızdan kan gelmesi, \% 51.2'sinde bulantı, \% 48.8'inde karın ağrısı, \%39.5'inde siyah dışkıen sık başvuru yakınmaları idi (Tablo 2). 
Sakarya Tip Dergisi 2021;11(1):53-60

GERÇEKER ve Ark., Çocuklarda Gastrointestinal Kanamaların Değerlendirilmesi

\begin{tabular}{|c|c|c|c|c|}
\hline \multicolumn{5}{|c|}{ Kanama Tipi } \\
\hline \multirow[b]{2}{*}{ Semptomlar } & \multicolumn{2}{|c|}{ Alt GİS kanaması } & \multicolumn{2}{|c|}{ Üst GİS kanaması } \\
\hline & Sayı & $\%$ & Sayı & $\%$ \\
\hline \multicolumn{5}{|l|}{ Ağızdan kan gelmesi } \\
\hline Evet & 3 & 11.1 & 36 & 83.7 \\
\hline Hayır & 24 & 88.9 & 7 & 16.3 \\
\hline \multicolumn{5}{|l|}{ Siyah Dışkı } \\
\hline Evet & 2 & 7.4 & 17 & 39.5 \\
\hline Hayır & 25 & 92.6 & 26 & 60.5 \\
\hline \multicolumn{5}{|l|}{ Karın ağrısı } \\
\hline Evet & 7 & 25.9 & 21 & 48.8 \\
\hline Hayır & 20 & 74.1 & 22 & 51.2 \\
\hline \multicolumn{5}{|l|}{ Bulantı } \\
\hline Evet & 2 & 7.4 & 22 & 51.2 \\
\hline Hayır & 25 & 92.6 & 21 & 48.8 \\
\hline \multicolumn{5}{|l|}{ Halsizlik } \\
\hline Evet & 6 & 22.2 & 10 & 23.3 \\
\hline Hayır & 21 & 77.8 & 33 & 76.7 \\
\hline \multicolumn{5}{|l|}{ Baş Dönmesi } \\
\hline Evet & 1 & 3.7 & 8 & 19.0 \\
\hline Hayır & 26 & 96.3 & 34 & 81.0 \\
\hline \multicolumn{5}{|l|}{ Dispepsi } \\
\hline Evet & - & 0.0 & 6 & 14.0 \\
\hline Hayır & 27 & 100.0 & 37 & 86.0 \\
\hline \multicolumn{5}{|l|}{ Rektal kanama } \\
\hline Evet & 25 & 92.6 & 1 & 2.3 \\
\hline Hayır & 2 & 7.4 & 42 & 97.7 \\
\hline \multicolumn{5}{|l|}{ Kabızlık } \\
\hline Evet & 19 & 70.4 & - & 0.0 \\
\hline Hayır & 8 & 29.6 & 43 & 100.0 \\
\hline Toplam & 27 & 100.0 & 43 & 100.0 \\
\hline
\end{tabular}

\begin{tabular}{|c|c|c|c|c|}
\hline \multicolumn{5}{|c|}{$\begin{array}{l}\text { Tablo 3: Gastrointestinal kanaması olan çocuklard } \\
\text { görülen fizik muayene bulguları } \\
\qquad \text { Kanama Tipi }\end{array}$} \\
\hline \multirow[b]{2}{*}{ Semptomlar } & \multicolumn{2}{|c|}{ Alt GİS kanaması } & \multicolumn{2}{|c|}{ Üst GİS kanaması } \\
\hline & Sayı & $\%$ & Sayı & $\%$ \\
\hline \multicolumn{5}{|c|}{ Fizik muayene bulguları } \\
\hline \multicolumn{5}{|l|}{ Hepatomegali } \\
\hline Evet & 2 & 7.4 & 4 & 9.3 \\
\hline Hayır & 25 & 92.6 & 39 & 90.7 \\
\hline \multicolumn{5}{|l|}{ Splenomegali } \\
\hline Evet & - & 0.0 & 3 & 7.0 \\
\hline Hayır & 27 & 100.0 & 40 & 93.0 \\
\hline \multicolumn{5}{|l|}{ Rektal tușede melena } \\
\hline Evet & 1 & 3.7 & 17 & 39.5 \\
\hline Hayır & 26 & 96.3 & 26 & 60.5 \\
\hline \multicolumn{5}{|l|}{ Taşikardi } \\
\hline Evet & 2 & 7.7 & 18 & 41.9 \\
\hline Hayır & 24 & 92.3 & 25 & 58.1 \\
\hline \multicolumn{5}{|l|}{ Solukluk } \\
\hline Evet & 9 & 33.3 & 25 & 58.1 \\
\hline Hayır & 18 & 66.7 & 18 & 41.9 \\
\hline \multicolumn{5}{|l|}{ Siroz } \\
\hline Evet & - & 0.0 & 2 & 4.7 \\
\hline Hayır & 27 & 100.0 & 41 & 97.1 \\
\hline \multicolumn{5}{|l|}{ Batında Kitle } \\
\hline Evet & - & 0.0 & 1 & 2.3 \\
\hline Hayır & 27 & 100.0 & 42 & 97.7 \\
\hline \multicolumn{5}{|l|}{ Rektal tuşede kitle } \\
\hline Evet & 13 & 48.1 & - & 0.0 \\
\hline Hayır & 14 & 51.9 & 43 & 100.0 \\
\hline Toplam & 27 & 100.0 & 43 & 100.0 \\
\hline
\end{tabular}

Üst GİS kanama nedeni ile endoskopi yapılan hastalardan 16 'sının (\% 37.3) NSAİI veya aspirin kullandığı ve bu hastaların 8'inin 2-5 yaş arasında olduğu saptanmıştır (2-5 yaşta 8 hasta, 6-11 yaşta 3 hasta, 12-17 yaşta 5 hasta). Alt Gís kanamalı hastaların \% 48.2'inde rektal tuşede kitle, \% 33.3'ünde solukluk, üst GIS kanamalı hastaların ise \% 58.1'inde solukluk, \% 41.9'unda taşikardi, \% 39.5'inde rektal tuşede melena en sık fizik muayene bulguları idi (Tablo 3).

Hastaların ortalama hemoglobin değeri $11.4 \pm 2.3$ (4.816.9) $\mathrm{g} / \mathrm{dL}$, ortalama hematokrit değeri \% $34.6 \pm 7.0$ (1552) ve ortalama OEH değeri $80.8 \pm 7.6 \mathrm{fl}$ (62.5-97.3) idi. Karaciğer, böbrek fonksiyon testleri ve koagülasyon parametreleri normaldi. Üst GİS kanamalı 16 hastada (\% 37.2) histopatolojik inceleme sonucunda $H$. pylori pozitifliği saptand 1 ve hastalara eradikasyon tedavisi verildi. Hastaların \% 60.5'inde normal patoloji saptanmıştır. Tirozinemiye bağlı hepatoselüler karsinom ve karaciğer sirozu olan 1 hasta bant ligasyonu yapılmasına rağmen özefagus varis kanaması nedeniyle kaybedildi. 
Alt GİS kanamalı 7 hasta (\% 25.9) histopatolojik inceleme sonucunda İBH (2 hasta crohn hastalığı, 5 hasta ülseratif kolit) tanısı almıştır. Hastaların \% 14.8'inde polip, \% 7.4'ünde Meckel divertikülü saptanmıştır (Tablo 4). Üst GİS kanamalı hastalarda histopatolojik inceleme sonucunda $H$. pylori saptananların \% 68.8'inde karın ağrısı saptanmiştır.

\begin{tabular}{|l|c|c|c|c|}
\hline $\begin{array}{l}\text { Tablo 4: Gastrointestinal kanaması olan çocuklarda kanama tipine göre } \\
\text { histopatoloji sonuçları }\end{array}$ \\
\hline \multicolumn{5}{|c|}{ Kanama Tipi } \\
\hline & GİS kanaması & Üst GİS kanaması \\
\hline Histopatoloji Sonuçları & Sayı & $\%$ & Sayı & $\%$ \\
\hline Helikobakter pylori & - & 0.0 & 16 & 37.2 \\
\hline İBH & 7 & 25.9 & - & 0.0 \\
\hline Meckel divertikülü & 2 & 7.4 & - & 0.0 \\
\hline Polip & 4 & 14.8 & 1 & 2.3 \\
\hline Granülomatoz kolit & 1 & 3.7 & - & 0.0 \\
\hline Normal patoloji & 13 & 48.1 & 26 & 60.5 \\
\hline Toplam & $\mathbf{2 7}$ & $\mathbf{1 0 0 . 0}$ & $\mathbf{4 3}$ & $\mathbf{1 0 0 . 0}$ \\
\hline GİS:Gastrointestinal, İBH: inflamatuar bağırsak hastalı̆̆1 & \\
\hline
\end{tabular}

\section{TARTIŞMA}

Üst ve alt GİS endoskopisi yapılan çocuklarda GİS kanamalarının etiyolojik nedenlerini ve sosyodemografik değişkenlerle ilişkisini retrospektif olarak incelediğimiz çalışmamızda, üst GİS kanamaları alt GİS kanamadan daha sık görülmüştür. Çocuklarda GİS kanamalarının sıklığı konusunda yeterli veri bulunmamaktadır. Yapılan çalışmalar genellikle pediatrik yoğun bakım ünitelerinde gerçekleştirilmiştir. Chaibou ve ark.'nın çalışmasında çocuk yoğun bakım ünitesine yatırılan 1006 çocuğun \% 10.2'sinin üst GİS kanama tanısı aldığ 1 bildirilmiştir. ${ }^{4}$ Lacroix ve ark.'nın çalışmasında çocuk yoğun bakım ünitesinde yatırılan 984 çocuğun \% 6.4'ünde üst GİS kanama gözlenmiştir. ${ }^{5}$ Pant ve ark.'nın Amerika'da hastanelerde yatırılarak tedavi edilen çocuklarda GİS kanama epidemiyolojisini araştırdığı çalışmasında, 23383 çocuk hastanın GİS kanama tanısıyla taburcu edildiği ve bu sayının tüm taburcuların \% 0.5 'ini oluşturduğu saptanmıştır. ${ }^{6}$

Yaklaşık iki yıllık süreçte, araştırma kriterlerine uyan tüm hastaları incelediğimiz çalışmamızda, GİS kanamalar 1217 yaş grubunda daha sık görülmüş olup, hastaların yaş ortalaması 11 yıl idi. Pant ve ark.'nın çalışmasında da, GİS kanama insidansı en sık 11-15 yaş grubunda görülmüş olup, en az 1 yaşından küçüklerde görülmüştür. ${ }^{6}$ Çocukluk döneminde, yaş gruplarına göre GİS kanama nedenleri değişebilmekte ve her yaşta çocukta kanama görülebilmektedir. Çalışmamızda GİS kanamaları her iki cinsiyette de eşit olarak saptanmıştır. Literatürde ise, erkek cinsiyette daha sık görüldüğü belirtilmekte olup, nedenine ilişkin bir veri mevcut değildir. ${ }^{6,7}$ Akçam ve ark.'nın çalışmasında, bizim çalışmamıza benzer olarak, üst Gİs kanama nedeniyle endoskopi yapılan 54 çocukta da, cinsiyet açısından fark saptanmamıştır. ${ }^{8}$

Üst GİS kanamalı hastaların etyolojisi incelendiğinde en sık eroziv gastrit/bulbit saptanmıştır. Yu ve ark.'nın 1218 Çinli çocuğu üst GİS kanama açısından inceledikleri retrospektif çalışmalarında, çocukların \% 76.4'ünde kanama kaynağı saptanmış olup, en sık rastlanan endoskopik bulgu eroziv gastrit (\% 33.5) ve duodenal ülser (\% 23.2) idi. Eroziv gastritin yaşla birlikte azaldığı, duodenal ülserin ise yaşla birlikte arttığını bildirmişlerdir. ${ }^{9}$ Bizim çalışmamızda ise, yaş gruplarına göre etyolojilerin benzer olduğu görülmüştür. Ünal ve ark.'nın çocuklarda üst GİS kanamalarının etyolojisini inceledikleri çalışmalarında, üst GİS kanamalarının \%15.1'inin varis ve \%70.5'inin varis dışı kaynaklı olduğunu saptamışlardır. ${ }^{2}$ Rafeey ve ark.'nın çalışmasında üst GİS kanamalı 447 çocuk hastada, en sık rastlanan endoskopik tanının özefajit ve eroziv özefajit olduğu belirtilmiştir. ${ }^{10}$ Mrad ve ark.'1 üst Gís kanamasıyla başvuran çocuklarda, süt çocuklarının \% 27.8'inde peptik özefajit, çocukların ise \%10'unda peptik özefajit, \%1.6'sında peptik ülser, \% 1.8'inde Mallory-Weiss yırtığ 1 ve \%1.6'sında varis tipi lezyonlar olduğunu bildirilmişlerdir. ${ }^{11}$ Literatüre benzer olarak, bizim çalışmamızda üst GİS kanamalı hastaların \% 69.8'i eroziv gastrit/bulbit, \% 16.2'si gastrik-duodenal ülser, \% 7'si özefageal varis, \% 4.7'si özefajit ve \% 2.3’ü vasküler malformasyon tanısı almıştır. 
Alt GİS kanamalı hastaların etyolojisi incelendiğinde en sık İBH saptanmıştır. Alt GİS kanamalı 7 hasta (\% 25.9) histopatolojik inceleme sonucunda İBH (2 hasta crohn hastalığg 5 hasta ülseratif kolit) tanısı almıştır. İBH, çocuklarda alt GİS kanamalarının en sık karşılaşılan sebeplerinden biridir. Çin'de her yaş grubunu içeren 53.951 hastayla yapılan bir çalışmada, kolerektal kanser-polip, kolit, anorektal hastalık ve İBH'nin yetişkin ve yaşlı populasyonunda; kolerektal polip, kronik kolit, invajinasyon ve İBH'nin de Çinli çocuklarda alt GİS kanamaların ana nedenleri olduğu belirtilmiştir. ${ }^{12}$

Khushdil ve ark.'nın 80 çocuk hastada alt GİS kanamaların etyolojisini inceledikleri çalışmalarında, en sık saptanan kolonoskopik tanı polipti (\% 58.7) ve kolon yerleşimliydi. Hastaların \% 21.2'sinde de kolit saptanmış olup çoğu 2-6 yaş arasındaydı. ${ }^{13}$ Polipler çocuklardaki GİS tümörlerinin en sık nedenidir ve alt GİS kanamanın önemli bir sebebidir. ${ }^{14}$ Çinli çocuklarla yapılan bir çalışmada, kolonoskopi yapılan 82 çocuğun \%50.6’sı ( $\mathrm{n}=40)$ tanı almış olup, 23 çocukta polip, 12 çocukta ise Crohn hastalığı saptanmıştır. Poliplerin \% 80'inin rektosigmoid kolonda olduğu belirtilmiştir. Aynı çalışmada, İBH'li çocukların yaş ortalaması 11.3 yıl, polipli çocukların yaş ortalaması ise 4.3 yıl olarak saptanmıştır. ${ }^{15}$ Bizim çalışmamızda da, yaş gruplarına göre alt GİS kanamalarının etyolojileri incelendiğinde ise, 2-5 yaş grubunda en sık anal fissür ve rektal polip , 6-11 yaş grubunda en sık İBH ve anal fissür, 12-17 yaş grubunda en sık İBH ve hemoroid saptanmıştır. İran'da 363 çocukla yapılan bir çalışmada da, alt GİS kanamalarının 2-10 yaş aralığında yaygın olduğunu, en sık kolonoskopik bulgunun sigmoid kolon polipi (\% 25.1) ve en sik patolojik bulgunun da juvenil polip (\% 23.1) olduğu belirtilmiştir. ${ }^{16}$ Aktif rektal kanaması olan 2-12 yaş arası 174 Mısırlı çocukla yapılan bir çalışmada da, hastaların \% 57.4'ünde rektal polip saptanmıştır. ${ }^{17}$ Rektal kanamalı 194 Mısırlı çocukta yapılan bir diğer çalışmada da, rektal kanamanın en sık sebebi enfeksiyöz enterokolit (\% 37.1) olup diğer sebepler sırasiyla kolerektal polip (\% 21.1), kronik kolit (\% 16), alerjik kolit (\% 2.6), soliter rektal ülser sendromu (\% 1.5) ve nonspesifik kolit (\% 6.7) idi. ${ }^{18}$ Thakkar ve ark.'nın çalışmasında alt GİS yakınması ile başvuran hastaların \% 12'sinde kolorektal polip saptadıkları, polipi olan hastaların yaşlarının, olmayanlardan daha küçük ve erkek cinsiyetin hakim olduğu (\% 58.3) bildirilmiştir. ${ }^{19}$ Bizim çalışmamızda da benzer olarak, rektal polip 2-5 yaş grubunda daha sıktır. Ek olarak hastaların \%14.8'inde polip, \%7.4'ünde Meckel divertikülü, \% 3.7’sinde granülomatoz kolit saptanırken, \% 48.1'inde patoloji sonucu normal bulunmuştur.

Üst GİS kanamalı hastaların başvuru yakınmaları incelendiğinde; \% 83.7'sinin hematemez, \% 51.2'sinin bulant1-kusma, \% 48.8'inin karın ağrısı, \% 39.5'inin melena, \% 23.3'ünün halsizlik ve \% 19'unun baş dönmesi nedeniyle başvurdukları saptanmıştır. Rafeey ve ark'nın çalışmasında üst GİS kanamalarında klinik bulgular sırasıyla, hematemez (\% 26.8), melena (\% 13.4) ve hematokezya (\% 2.4) olarak saptanmıştır. ${ }^{10}$ Diğer bir çalışmada da, klinik bulgular sirasiyla, hematemez (\% 59.3), melena (\% 22.6) ve her iki bulgu birden hastaların \% 18.12'sinde saptanmıştır. Diğer önemli semptomlar ise abdominal ağrı (\% 46.2) ve halsizlik (\% 6.3) olup, hastaların \% 2.2'sinde hipovolemik şok saptanmış, \% 11'ine transfüzyon uygulanmıştır. ${ }^{9}$ Çalışmamızda, hematemez en sık rastlanan semptomdu. Bu durum diğer araştırmalarda da gözlenmektedir. ${ }^{9,10}$

Hematemez ve melena her ikisi de ciddi kanamalardır, çalışmamızda tüm hastaların ortalama hemoglobin değeri $11.4 \pm 2.3$ (4.8-16.9) g/dl, ortalama hematokrit değe-

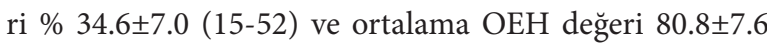
(62.5-97.3) fl idi. Yu ve ark.'nın çalışmasında hematemez ve melenanın her ikisinin birden görüldüğü grupta, $\mathrm{Hb}$, $\mathrm{OEH}$ değerlerinin sadece hematemez ya da melena görülen gruptan daha düşük olduğu saptanmıştır. ${ }^{9}$

Alt GİS kanamalı hastaların başvuru yakınmaları incelendiğinde; \%92.6’sının hematokezya, \% 70.4'ünün kabızlık, \% 25.9’unun karın ağrısı, \% 22.2’sinin halsizlik, \%7.4’ünün melena ve bulantı-kusma ve \% 3.7'sinin baş dönmesi nedeniyle başvurdukları saptanmıştır. İran'da yapılan bir ça- 
lışmada da, alt GİS kanamalı hastaların \%80.2'sinde hematokezya, \%18.1'inde kanlı diyare ve \%1.7'sinde pozitif gizli kan bulgusu saptanmıştır. ${ }^{16}$ Aktif rektal kanaması olan 174 Mısırlı çocukla yapılan bir çalışmada da, aktif rektal kanamanın yanısıra 74 çocukta farklı nedenler saptanmıştır. $\mathrm{Bu}$ nedenler intestinal amebiazis (42), diyare (18), ciddi konstipasyon (2) ve intestinal şistosomiazis (2) idi. ${ }^{17}$ Okul öncesi ve okul çağı çocuklarında rektal kanamanın en sık sebebi fissür formasyonu ile birlikte konstipasyon olabilir. Alt GİS kanamaları yaşa göre farklı bulgular sergileyebilir. Eğer çocukta hipovolemi bulgusu varsa, hemodinamik stabilizasyon sağlanmalı, aktif kanama durdurulmalı ve tekrarlayan kanama önlenmelidir. ${ }^{20}$

Üst GİS kanama nedeni ile endoskopi yapılan hastalardan 16’sının (\% 37.3) NSAİİ veya aspirin kullandığı ve bu hastaların 8'inin 2-5 yaş arasında olduğu saptanmıştır. Kalyoncu ve ark.'nın 2 yaşından küçük 34 çocukta GİS kanama etyolojisini incelediği çalışmasında da, hastaların \%56'sının NSAIIİ aldığı belirtilmiştir. ${ }^{7}$ Ünal ve ark.’’ da çalışmalarında, hastaların \%26.6’sında ilaç kullanım öyküsünün mevcut olduğu, en sık 3-9 yaş grubu hastaların ilaç kullanmakta olduğunu saptamışlardır (\% 25.9). ${ }^{2}$ Küçük yaş gruplarında antipiretik kullanımına bağlı olarak üst GİS kanama insidansının çalışmamızdakine benzer olarak artmış olabileceği düşünülmektedir.

Bu çalışmada, üst GİS kanamalı 16 hastada (\% 37.2) histopatolojik inceleme sonucunda $H$. pylori pozitifliği saptand1 ve hastalara eradikasyon tedavisi verildi. Hastaların \% 2.3'ünde vasküler malformasyon saptanırken, \% 60.5'inde normal patoloji saptanmıştır. Mrad ve ark.'1 üst GİS kanamasıyla başvuran çocuklarda, 614 endoskopik değerlendirmenin \% 20.6'sında endoskopik olarak etyoloji saptamamışlardır. ${ }^{11}$ Üst GİS endoskopisi, üst GİS kanamalarının altında yatan nedeni saptamada tanısal bir prosedürdür, bu sayede çeşitli endoskopik lezyonlar görülerek uygun tedavi sağlanabilir. ${ }^{10}$ Akçam ve ark.'nın çalışmasında da, hastaların \% 40'ında $H$. pylori pozitifliği saptanmıștır. ${ }^{8}$ Ülkemizde yapılan bir çalışmada da, GİS yakınması olan endoskopi yapılan 357 çocuğun \% 13.2'sinde peptik ülser hastalığı saptandığı, 47 peptik ülser hastasının 38'inde H.pylori pozitif olduğu bildirilmiştir. ${ }^{21}$ Çalışmamızda, üst GİS kanamalı hastalarda patoloji sonucunda $H$. pylori saptananların \% 68.8'inde karın ağrısı saptanmıştır. Ecevit ve ark.'nın çalışmasında endoskopi yapılan 902 çocuk hastanın \% 3.4'ünde peptik ülser hastalığı saptanmış olup, ülseri olan hastaların \% 61'inde H.pylori pozitifliği bildirilmiştir. $^{22} \mathrm{Bu}$ çalışmada H.pylori pozitif grupta üst GİS kanaması ve ağrı major semptomlar olarak belirtilmiştir. Ağrı semptomu ve H. pylori ilişkisini açıklayabilecek çalışmalara ihtiyaç duyulmaktadır.

Sonuç olarak NSAİI kullanımına bağlı üst GİS kanaması olgularının yarısının 2-5 yaş döneminde ortaya çıktığı ve ergenlik dönemdeki alt GİS kanamalarının önemli nedenlerinden birisinin İBH olduğu saptanmıştır. Buna göre NSAİI kullanımında dikkatli olunması ve ergenlik dönemindeki alt GİS kanamalarında İBH açısından değerlendirme yapılmasının önemli olduğu düşünülmüştür.

\section{Çalışmanın Kısıtlılı̆̆ı}

Çalışmanın tek bir hastanede yürütülmesi ve katılımcı sayısının az olması araştırmanın sınırlılıklarını oluşturmaktadir.

\section{Çıkar Çatışması}

Yazarlar çıkar çatışması bildirmemiştir.

\section{Etik onay}

Çalışma protokolü Celal Bayar Üniversitesi Hafsa Sultan Hastanesi Yerel Etik Kurulu tarafından onaylanmıştır (03/08/2016 20.478.486-282). 
Sakarya Tip Dergisi 2021;11(1):53-60

GERÇEKER ve Ark., Çocuklarda Gastrointestinal Kanamaların Değerlendirilmesi

\section{Kaynaklar}

1. Wyllie R, Hyams JS, Kay M. Pediatric gastrointestinal and liver disease. 5th ed., Elsevier Health Sciences; 2015.

2. Unal F, Şahin G, Ecevit Ç, Semizel E, Cebe A, Erdoğan H, et al. Çocuklarda Üst Gastrointestinal Sistem Kanamalarına Tanısal ve Tedavi Edici Endoskopik Yaklaşımlar. Güncel Pediatr 2012;10:1-7.

3. Kasırga E. Çocukluk Çağında Gastrointestinal Sistem Kanamaları. Türkiye Klin J Pediatr Sci 2005;1(8):21-31.

4. Chaïbou M, Tucci M, Dugas MA, Farrell CA, Proulx F, Lacroix J. Clinically significant upper gastrointestinal bleeding acquired in a pediatric intensive care unit: a prospective study. Pediatrics 1998;102:933-8.

5. Lacroix J, Nadeau D, Laberge S, Gauthier M, Lapierre G, Farrell CA. Frequency of upper gastrointestinal bleeding in a pediatric intensive care unit. Crit Care Med 1992;20(1):35-42.

6. Pant C, Sankararaman S, Deshpande A, Olyaee M, Anderson MP, Sferra TJ. Gastrointestinal bleeding in hospitalized children in the United States. Curr Med Res Opin 2014;30(6):1065-9.

7. Kalyoncu D, Urganci N, Cetinkaya F. Etiology of upper gastrointestinal bleeding in young children. Indian J Pediatr 2009;76(9):899-901.

8. Akçam M, Yllmaz A, Artan R. Üst gastrointestinal kanama nedeniyle endoskopi yapılan çocuklar: 54 hastanın retrospektif değerlendirilmesi. SDÜ Tip Fak Derg 2006;13(1):22-6.

9. Yu Y, Wang B, Yuan L, Yang H, Wang X, Xiao Y, et al. Upper Gastrointestinal Bleeding in Chinese Children: A Multicenter 10-Year Retrospective Study. Clin Pediatr 2015;(197):1-6.

10. Rafeey M, Shoaran M, Majidy H. Diagnostic endoscopy and clinical characteristics of gastrointestinal bleeding in children: a 10-year retrospective study. Iran Red Crescent Med J 2013;15(9):794-7.

11. Mrad SM, Boukthir S, Brini I, Hachicha S, Samoud A. Endoscopic diagnosis in a Tunisian pediatric population with upper gastrointestinal bleeding. Tunis med 2013;91(11):655-60.
12. Bai Y, Peng J, Gao J, Zou D-W, Li Z-S. Epidemiology of lower gastrointestinal bleeding in China: single-center series and systematic analysis of Chinese literature with 53,951 patients. J Gastroenterol Hepatol 2011;26(4):678-82.

13. Khushdil A, Ali S, Malik R, Farrukh H. Etiology Of Lower Gastrointestinal Bleeding In Paediatric Patients, A Colonoscopic Surgery. Armed Forces Med J 2014;64(3):484-7.

14. Nikpour S, Ali Asgari A. Colonoscopic evaluation of minimal rectal bleeding in average-risk patients for colorectal cancer. World J Gastroenterol 2008;14(42):6536-40.

15. Tam YH, Lee KH, Chan KW, Sihoe JDY, Cheung ST, Mou JWC. Colonoscopy in Hong Kong Chinese children. World J Gastroenterol 2010;16(9):1119-22.

16. Zahmatkeshan M, Fallahzadeh E, Najib K, Geramizadeh B, Haghighat M, Imanieh MH. Etiology of lower gastrointestinal bleeding in children: a single center experience from southern iran. Middle East J Dig Dis 2012;4(4):216-23.

17. El-Shabrawi MHF, El Din ZE, Isa M, Kamal N, Hassanin F, El-Koofy N, et al. Colorectal polyps: a frequently-missed cause of rectal bleeding in Egyptian children. Ann Trop Paediatr 2011;31(3):213-8.

18. El-Khayat HA, El-Hodhod MA, Abd El-Basset FZ, Tomoum HY, El-Safory HA, Hamdy AM. Rectal bleeding in Egyptian children. Ann Trop Paediatr 2006;26(4):337-44.

19. Thakkar K, Alsarraj A, Fong E, Holub JL, Gilger MA, El Serag HB. Prevalence of colorectal polyps in pediatric colonoscopy. Dig Dis Sci 2012;57(4):1050-5.

20. Leung AKC, Wong AL. Lower gastrointestinal bleeding in children. Pediatr Emerg Care 2002;18(4):319-23.

21. Uğraș M, Pehlivanoğlu E. Helicobacter pylori infection and peptic ulcer in eastern Turkish children: is it more common than known? Turk J Pediatr 2011;53(6):632-7.

22. Ecevit ÇÖ, Özgenç F, Yüksekkaya HA, Unnal F, Arikan Ç, Yağci RV. Peptic ulcer disease in children: an uncommon disorder with subtle symptomatology. Turkish J Gastroenterol 2012;23(6):666-9. 